\title{
Particle size distribution and particle mass measurements at urban, near-city and rural level in the Copenhagen area and Southern Sweden
}

\author{
M. Ketzel ${ }^{1,2}$, P. Wåhlin ${ }^{1}$, A. Kristensson ${ }^{2}$, E. Swietlicki ${ }^{2}$, R. Berkowicz ${ }^{1}$, O. J. Nielsen ${ }^{3}$, and F. Palmgren ${ }^{1}$ \\ ${ }^{1}$ Department of Atmospheric Environment, National Environmental Research Institute, Roskilde, Denmark \\ ${ }^{2}$ Division of Nuclear Physics, Physics Department, Lund University, Lund, Sweden \\ ${ }^{3}$ Department of Chemistry, University of Copenhagen, Denmark
}

Received: 17 September 2003 - Published in Atmos. Chem. Phys. Discuss.: 3 November 2003

Revised: 3 February 2004 - Accepted: 4 February 2004 - Published: 13 February 2004

\begin{abstract}
Particle size distribution (size-range 3-900 nm) and PM10 was measured simultaneously at an urban background station in Copenhagen, a near-city background and a rural location during a period in September-November 2002. The study investigates the contribution from urban versus regional sources of particle number and mass concentration.

The total particle number $(\mathrm{ToN})$ and $\mathrm{NO}_{\mathrm{x}}$ are well correlated at the urban and near-city level and show a distinct diurnal variation, indicating the common traffic source. The average $\mathrm{ToN}$ at the three stations differs by a factor of 3 . The observed concentrations are $2500 \# \mathrm{~cm}^{-3}, 4500 \mathrm{~cm}^{-3}$ and

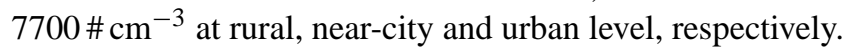

PM10 and total particle volume (ToV) are well correlated between the three different stations and show similar concentration levels, in average within 30\% relative difference, indicating a common source from long-range transport that dominates the concentrations at all locations.
\end{abstract}

Measures to reduce the local urban emissions of $\mathrm{NO}_{\mathrm{x}}$ and $\mathrm{ToN}$ are likely to affect both the street level and urban background concentrations, while for PM10 and ToV only measurable effects at the street level are probable. Taking into account the supposed stronger health effects of ultrafine particles reduction measures should address particle number emissions.

The traffic source contributes strongest in the $10-200 \mathrm{~nm}$ particle size range. The maximum of the size distribution shifts from about $20-30 \mathrm{~nm}$ at kerbside to $50-60 \mathrm{~nm}$ at rural level. Particle formation events were observed in the 3$20 \mathrm{~nm}$ size range at rural location in the afternoon hours, mainly under conditions with low concentrations of preexisting aerosol particles.

The maximum in the size distribution of the "traffic contribution" seems to be shifted to about $28 \mathrm{~nm}$ in the urban

Correspondence to: M. Ketzel

(mke@dmu.dk) location compared to $22 \mathrm{~nm}$ at kerbside. Assuming $\mathrm{NO}_{\mathrm{x}}$ as an inert tracer on urban scale allows to estimate that ToN at urban level is reduced by 15-30\% compared to kerbside. Particle removal processes, e.g. deposition and coagulation, which are most efficient for smallest particle sizes $(<20 \mathrm{~nm})$ and condensational growth are likely mechanisms for the loss of particle number and the shift in particle size.

\section{Introduction}

During recent years the concerns about health effects of particles have increased considerably. This is partly due to results from epidemiological surveys showing that there is a correlation between the mass concentration of particles, and mortality and hospitalisation. (Künzli et al., 2000). Particle mass concentrations (later referred to as PM, including PM2.5 and PM10) are therefore regulated e.g. in the US and EU legislation. However, the ultrafine particles (UFP, i.e. diameters less than $0.1 \mu \mathrm{m}$ ) are considered especially detrimental to human health, since these particles can be inhaled and deposited deep in the alveoli of human lungs (Seaton et al., 1995). Moreover, epidemiological studies suggest a connection between both UFP and PM concentration and mortality (Wichmann and Peters, 2000). Effects of PM were clearer in respiratory cases, whereas effects of UFP were clearer in cardiovascular cases.

The investigation of primary aerosol sources, especially for soot, and their interaction with secondary aerosols receive currently attention due to their impact on radiative forcing and global climate change (Jacobson, 2001).

Urban pollution plays an important role due to a high concentration of particle sources and a large population exposed to elevated particle concentrations. To better characterise the urban particle sources and the fate of the particles in the 


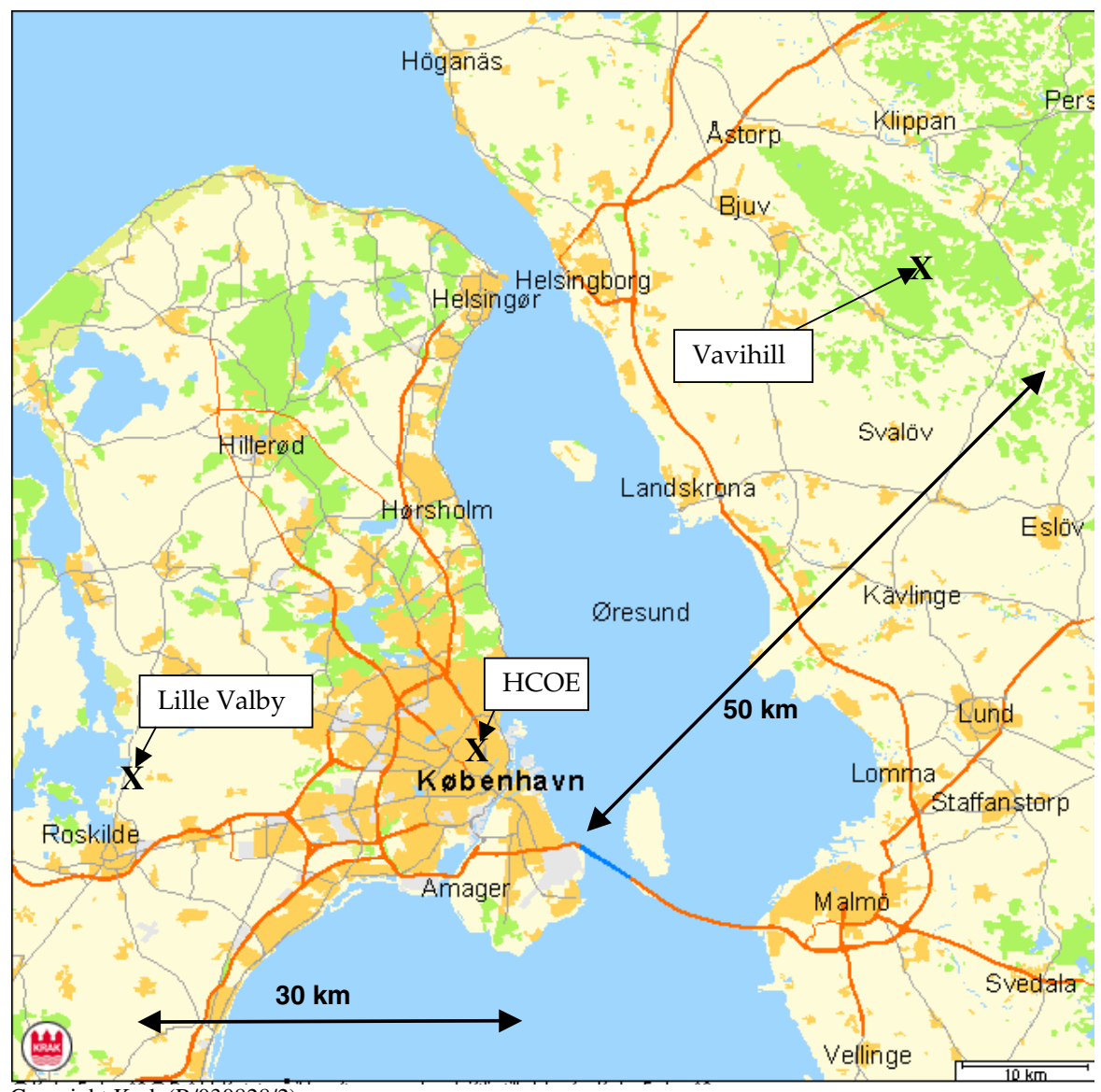

Copyright Krak (R/030828/2)

Fig. 1. Map of the Øresund region with location of the monitoring stations Lille Valby (LVBY, near-city background), H. C. Ørsted Institute (HCOE, urban background) and Vavihill (VVHL, rural background).

atmosphere there is a need to perform field measurements. Since climatic conditions and sources as e.g. the composition of the vehicle fleet can be different from country to country, results can not be transferred from location to location.

Extensive measuring programs of urban and regional aerosol concentration have been carried out at several locations: e.g. Leipzig (Wehner and Wiedensohler, 2003), Nordic background stations (Tunved et al., 2003), Zurich area (Bukowiecki et al., 2003). In a previous Danish campaign the traffic source was studied by analysing simultaneous street level and urban background measurements in Copenhagen (Ketzel et al., 2003).

The purpose of this study is to investigate the contribution from urban and suburban sources to the elevation of particle number and particle mass concentrations in cities compared to background levels. The contributions from long-range transport and from local sources are estimated. We document results of a measuring campaign that was performed at an urban background station located close to the centre of Copenhagen and two background locations west and north-east of the city. For some of the measured compounds (e.g. particle mass) the contribution from long-range transport dominates. Therefore it is essential to perform simultaneous measurements since only small differences might appear on top of a highly variable regional background. The difference between urban and background concentration levels show the potential for reduction scenarios that would influence the urban emissions, e.g. mandatory particle traps for certain part of the vehicle fleet or traffic reduction in the city centre. Analysing the particle size distribution in the urban background and comparing with the street contribution will give an indication about particle transformation processes that act on the particles on their way from the street to the urban background levels.

\section{Experimental}

\subsection{Sampling location and period}

The location of the three main sampling sites in this study is given in Fig. 1. Two stations belong to the Danish Air Quality 
Table 1. 1 Average of measured particle concentrations and $\mathrm{NO}_{\mathrm{x}}$ at three background and two street stations. The average includes only records where data at all three background stations were available and only working days, except stated otherwise ( $\mathrm{N}=481$, based on half hourly values).

\begin{tabular}{lcccccc}
\hline & unit & VVHL rural & LVBY near-city & HCOE urban & JGTV kerbside & HCAB kerbside \\
\hline ToN $(>10 \mathrm{~nm})$ & $\# / \mathrm{cm}^{3}$ & 2520 & 4460 & 7670 & $24100^{a}$ & $43400^{a}$ \\
ToV $(<0.7 \mu \mathrm{m})$ & $\mu \mathrm{m}^{3} / \mathrm{cm}^{3}$ & 4.6 & 6.1 & 6.5 & $12.3^{a}$ & $17.9^{a}$ \\
$\mathrm{PM} 10-\mathrm{TEOM}$ & $\mu \mathrm{g} / \mathrm{m}^{3}$ & $9.0^{b}$ & 9.5 & 10.3 & 17.2 & 29.5 \\
$\mathrm{NO}_{\mathrm{x}}$ & $\mathrm{ppb}$ & & 11.4 & 14.8 & 84.0 & 128.4 \\
\hline
\end{tabular}

$a_{\text {results from measuring periods in 2001/2002 }}$

$b$ based on all available simultaneous measurements of PM10 at VVHL and LVBY

Monitoring Programme (Kemp and Palmgren, 2003), the urban background location at the roof of the $20 \mathrm{~m}$ high H. C. Ørsted Institute (HCOE; $12^{\circ} 33^{\prime} 42^{\prime \prime} \mathrm{E}, 55^{\circ} 42^{\prime} 2^{\prime \prime} \mathrm{N}$ ) and the background location Lille Valby (LVBY; $12^{\circ} 7^{\prime} 34^{\prime \prime} \mathrm{E}$, $\left.55^{\circ} 41^{\prime} 14^{\prime \prime} \mathrm{N}\right)$ ca. $30 \mathrm{~km}$ west of Copenhagen. Lille Valby can be characterised as near-city background because of the influence of the greater Copenhagen area in the east and the town of Roskilde in the south.

Another background station Vavihill (VVHL; $13^{\circ} 09^{\prime} \mathrm{E}$, $56^{\circ} 01^{\prime} \mathrm{N}$ ) is located in Sweden ca. $25 \mathrm{~km}$ east of Helsingborg and ca. $50 \mathrm{~km}$ north-east of Copenhagen and is operated by the Lund University, Sweden. The Vavihill site lies in the middle of a forest area (Söderåsen), is part of the EMEP network (www.emep.int) and can be considered as rural background site.

The measurements at VVHL and HCOE are conducted for several years while the particle measurements at LVBY were operated only during the period 27 September-6 November 2002. Selecting data records for which particle size measurements from all three locations are available, forms a sub-set of 2.5 weeks of data, which will be analysed in this work. The periods for the sub-set are: 27 September-1 October; 11-22 October; 25-29 October and 4-6 November.

For the purpose of comparing the urban regional particle size distribution with the "fresh" source contribution particle and $\mathrm{NO}_{\mathrm{x}}$ data were used from two kerbside stations in Copenhagen, Jagtvej (JGTV) and H. C. Andersens Boulevard (HCAB) belonging to the Danish Monitoring Program and the Municipality of Copenhagen, respectively. The particle size distribution data from these stations were obtained during several periods through 2001/2002 and only data were used for which simultaneous urban background measurements (at HCOE) are available. The mean temperatures for this data set are with values of $12^{\circ} \mathrm{C}-13^{\circ} \mathrm{C}$ close to the yearly average in Copenhagen of about $10^{\circ} \mathrm{C}$. The average daily traffic at JGTV and HCAB is ca. 26000 and 60000 vehicles per day, respectively. The heavy vehicle share is $5-8 \%$.

\subsection{Instrumentation and data processing}

At all sites, Differential Mobility Particle Sizers (DMPS) consisting of Vienna-type Differential Mobility Analysers (DMA) (Winklmayr et al., 1991) and employing a recirculating flow system (Jokinen and Mäkelä, 1997) were used to measure the particle number size distribution. The DMPS at the Danish sites used a single DMA of $28 \mathrm{~cm}$ length and particles were counted using a TSI® Model 3010 Condensation Particle Counter (CPC). The scanning time for each size spectrum was 3 min, using alternating up- and down-scans. At Vavihill (VVHL) a DMPS setup with a twin DMA was employed, where an $11 \mathrm{~cm}$ DMA was used for the interval $3-22 \mathrm{~nm}$ diameter in connection with a TSI ${ }^{\circledR}$ Model 3025 CPC and a $28 \mathrm{~cm}$ DMA for the interval 22 $900 \mathrm{~nm}$ diameter with a TSI® Model 3760 CPC. Corrections for reduced counting efficiency at lower sizes, multiple charging (Wiedensohler, 1988) and particle sampling losses were made at the three stations.

All DMA were build and calibrated (for the loss and broadening parameters of the transfer function) at the Lund University. The Danish DMPS are intercompared on a regular basis, showing very good agreement between the instruments, typically 5-15\% difference in the total number concentrations. The performance of the DMPS systems at the background sites is regularly checked by comparing the total number concentration estimated by integrating the size distribution and the number concentration given by the CPC operating alone. These values should agree within a few percent. Average spectra for each half-hour were calculated and used for the analysis in relation to the trace gas and meteorological measurements. The total particle number (ToN) and volume (ToV) was estimated for each half-hour based on the single scans assuming spherical particles and considering the overlapping size range of 10-700 $\mathrm{nm}$ for all DMPS.

At the Danish stations half-hourly measurements $\mathrm{NO}_{\mathrm{x}}$ are available employing monitors by API Inc., CA (model M 200A). At all stations PM10 (mass concentration of particles with aerodynamic diameter less than $10 \mu \mathrm{m}$ ) was measured using a Tapered Element Oscillating Microbalance 

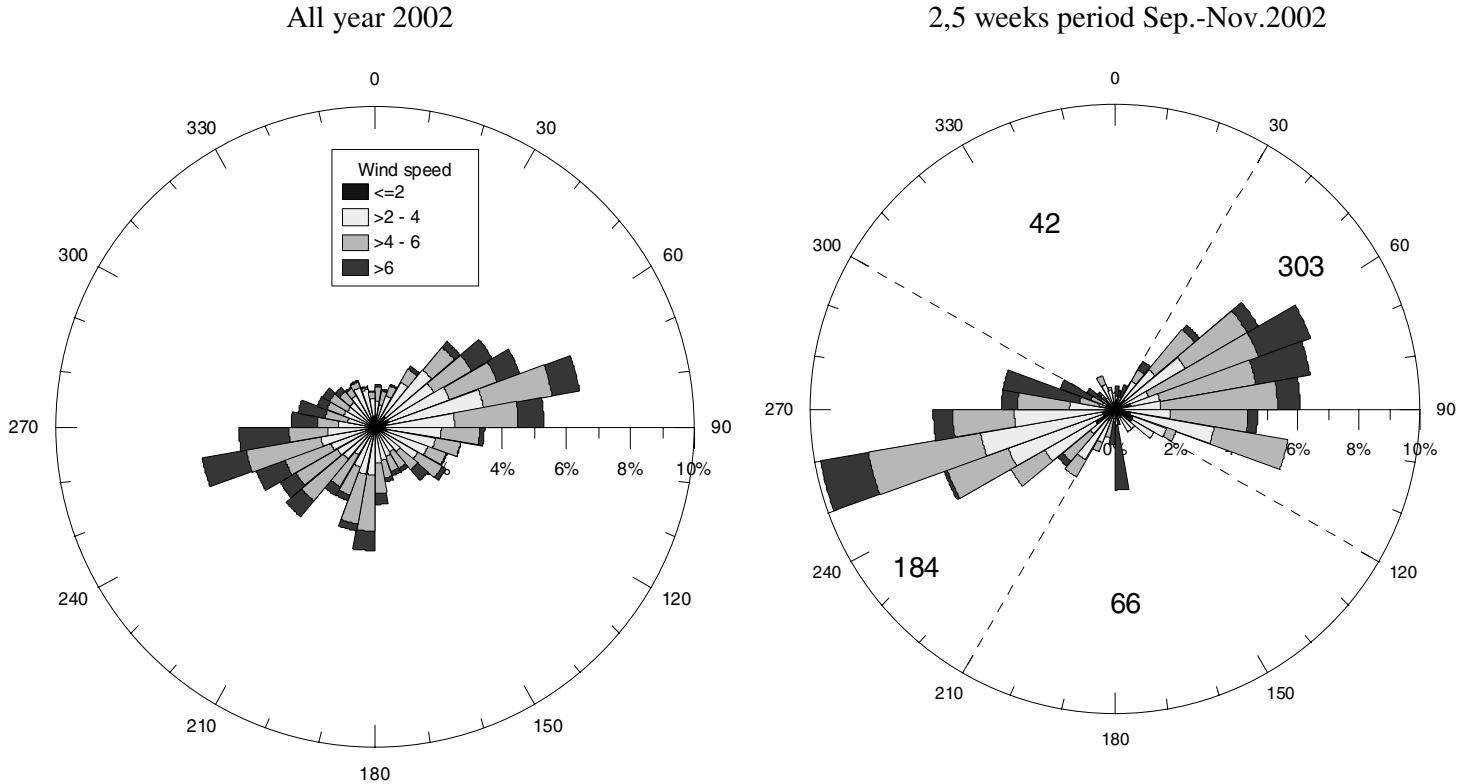

Fig. 2. Frequency distribution of wind direction and wind speed measured at HCOE for the year 2002 (left plot) and the observation period in Sep-Nov 2002 with simultaneous measurements (right). The right plot also shows the division in wind direction sectors as used for Fig. 8 and the number of measured half hour records (only working days) in each sector.

(TEOM, R\&P Inc.). The TEOM are operated at $50^{\circ} \mathrm{C}$ in order to dry the aerosol. This increased temperature leads to losses of volatile compounds (e.g. ammonium nitrate) in the TEOM and in general smaller PM10 values compared to PM10 results using a gravimetric or beta-attenuation method. For the stations JGTV and HCOE this difference between PM10 1 TEOM and PM10 $0_{\text {beta }}$ was compared for daily averages during several months indicating a similar difference at both stations with a mean value of about $10 \mu \mathrm{g} / \mathrm{m}^{3}$ (Palmgren et al., 2003; Wåhlin and Palmgren, 2003). The fact that the PM10 losses is similar at kerbside (JGTV) and urban background (HCOE) let us conclude that mainly the long-range contribution to PM10 contains the volatile substances while the local contribution (i.e. exhaust-soot and road dust resuspension) are less effected by volatilisation.

British and Swedish studies suggest a factor of 1.3 to correct for PM10 losses in the TEOM (APEG, 1999; Ferm and Hansson, 2003). Our investigations yield a ratio PM10 beta $/$ PM10 10 TEOM of 1.5 and 1.7 for kerbside (JGTV) and urban (HCOE) locations respective.

As reference Table 1 shows the average values of the measured compounds at all locations used in this study.

\subsection{Meteorological measurements}

The HCOE roof site is equipped with a meteorological station at $10 \mathrm{~m}$ height above roof level measuring the following parameters: wind direction (WD), wind speed (WS), relative humidity $(\mathrm{RH})$, temperature $(\mathrm{T})$, and solar radiation. The same meteorological parameters are available from a $10 \mathrm{~m}$ mast at LVBY, operated by Ris $\emptyset$ National Laboratory.

It has been shown that the WD and WS at HCOE is representative for the regional wind flow. The time series plots in Sect. 3.1 document a good correlation of WD and WS between HCOE and LVBY. Similar agreement was found between meteorological measurements at $\mathrm{HCOE}$ and at Copenhagen airport ( $15 \mathrm{~km}$ south east of the city centre). At VVHL the height of the meteorological mast is smaller than the surrounding forest and therefore the data show a clear influence from the forest canopy. These date do not represent the regional wind flow and are not used in this analysis, for instance the average wind speed at VVHL is only $0.8 \mathrm{~m} / \mathrm{s}$ compared to $3.8 \mathrm{~m} / \mathrm{s}$ and $3.6 \mathrm{~m} / \mathrm{s}$ at HCOE and LVBY respectively.

The wind charts for the year 2002 and for the period of simultaneous measurements are shown in Fig. 2. The year 2002 has a much higher share of easterly wind directions than the 10-year average, where usually winds from west and south west are by far dominating (DMI, 2003). Our measuring period reflects this high share of easterly winds as well (right plot in Fig. 2). Considering that only a subset of 2.5 weeks of data was available the similarities with the complete year 2002 are satisfying in terms of the general east-west orientation of the wind distribution and our measuring period can be regarded as representative. Also shown in Fig. 2 is a division in wind direction sectors. We have chosen to group the data in order to document the wind direction dependence of the particle size distribution. Divisions are made at $30^{\circ}$, $120^{\circ}, 210^{\circ}$ and $300^{\circ}$. 


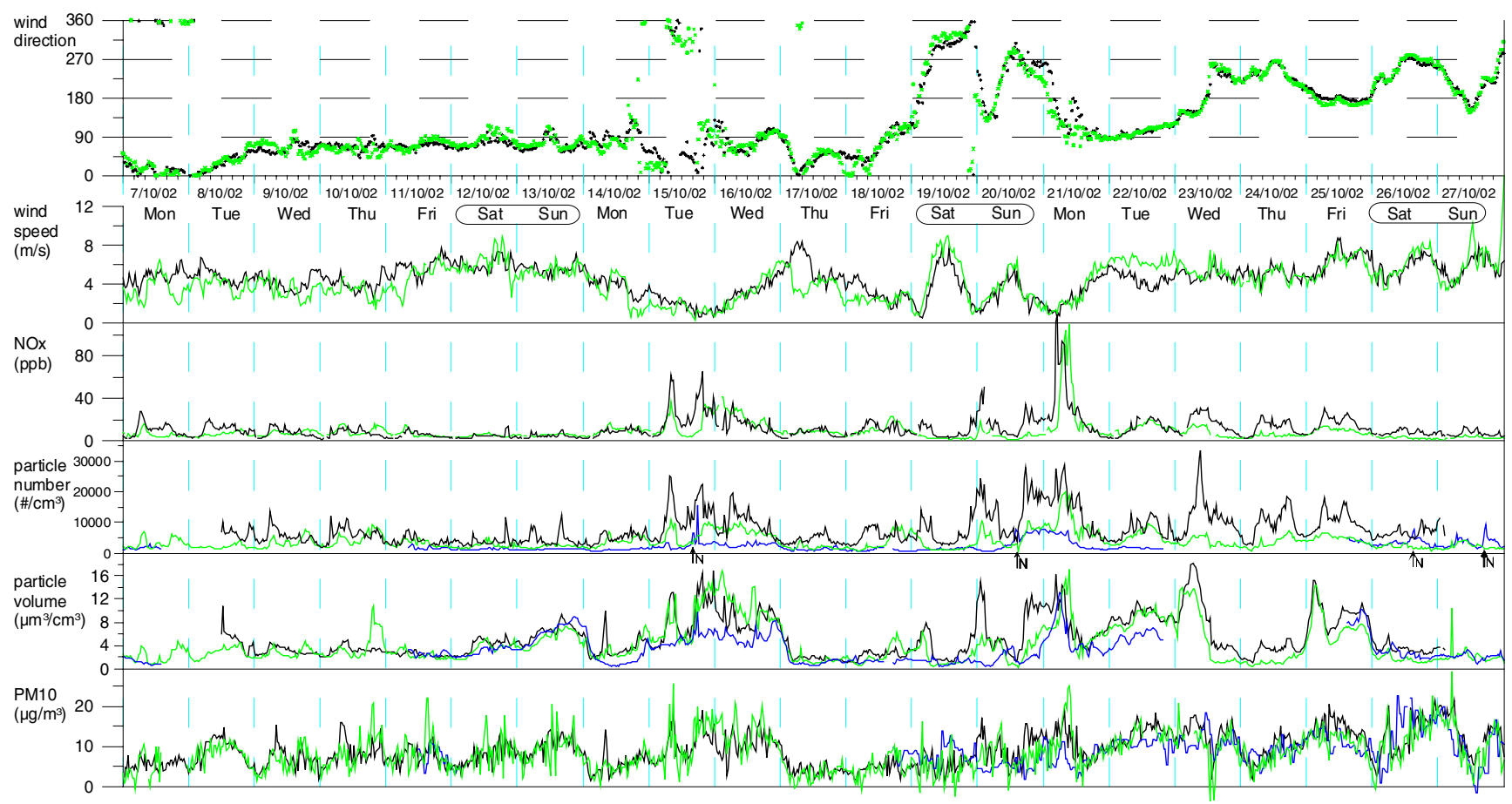

Fig. 3. Time series over 3 weeks period (7.10.-27.10.2002) for measured pollutant concentration and meteorology. For PM10, ToN and ToV values at the three stations VVHL (blue line), LVBY (green) and HCOE (black) are available. Wind speed, wind direction and $\mathrm{NO}_{\mathrm{x}}$ are only available at HCOE and LVBY. The vertical lines mark midnight. The arrows under the particle number plot indicate particle formation events observed at VVHL.

\section{Results and discussion}

\subsection{Time series and diurnal pattern of total concentrations}

A time series of WD, WS, $\mathrm{NO}_{\mathrm{x}}$, ToN, ToV and PM10 for part of the measuring period is shown in Fig. 3.

$\mathrm{NO}_{\mathrm{x}}$ and ToN appear to have a relative constant "regional" background level of 5-10 ppb and $2000-4000 \# \mathrm{~cm}^{-3}$ and in most night hours the concentrations decrease to these low levels. Superimposed on this background a diurnal pattern was observed at the urban (HCOE) and near-city (LVBY) location reflecting the variations of the urban source. High WS tend to lower the levels of $\mathrm{NO}_{\mathrm{x}}$ and ToN due to higher dilution (see e.g. 12.,13.,17. and 19.10. in Fig. 3), while low WS lead to higher concentration (15., 20. and 21.10.). ToN at the rural location (VVHL) does not show a typical diurnal behaviour due to the absence of local traffic sources. Instead particle formation events were observed at VVHL, typically in the early afternoon (marked by arrows in Fig. 3).

ToV and PM10 follow an episodic pattern in which particle concentrations are higher over periods of several days and decrease again, often related with a change of weather situation and new air masses and a sudden change in WD and/or WS. Such episodes of high ToV and PM10 are e.g. observed on 12.+13.10., 15.+16.10. and 21.-23.10. (Fig. 3). The concentration levels at the three stations behave very similar dur- ing such episodes (especially 12.+13.10.) which indicates the long-range origin of these concentrations. A diurnal pattern in ToV and PM10 is hard to identify in the time series at HCOE and LVBY due to the dominating long-range contribution. Low wind speeds tend to increase the difference between the levels observed at HCOE and LVBY relative to VVHL (e.g. 15. and 20.10.). This shows the presence of local sources of PM10 and ToV found in the urban region.

In general PM10 and ToV trace each other for the above described episodes. An exception is observed on 26.+27.10. where an episode of elevated PM10 levels is not accompanied be elevated ToV levels, i.e. only coarse particles were present.

The scatter seen in the PM10-TEOM time series is substantially higher compared to e.g. ToV or $\mathrm{NO}_{\mathrm{x}}$. For TEOM data a 2-3 hour running average seems to be appropriate to filter the high frequency fluctuations.

The diurnal variation of $\mathrm{NO}_{\mathrm{x}}$ and $\mathrm{ToN}$ is more visible when all data are grouped into working days, Saturday and Sundays and averaged separately for each hour of the day as shown in Fig. 4. The highest concentrations for all compounds are generally observed at HCOE and the lowest at VVHL, although exceptions in this ranking can appear. For instance lead the particle formation events, observed at VVHL in the afternoon hours, to an increase of the particle number concentration at VVHL, reaching similar or 


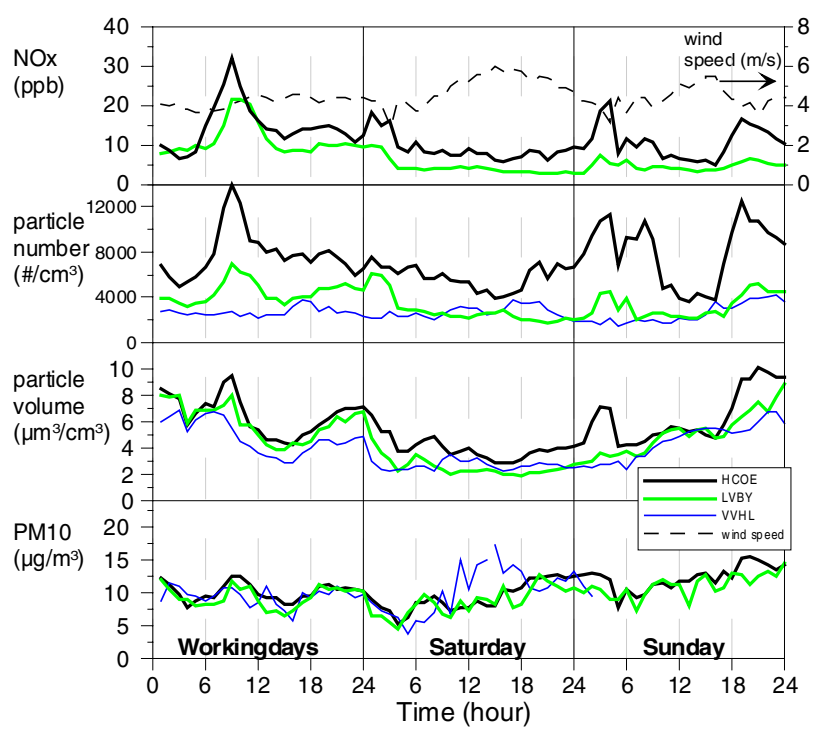

Fig. 4. Average diurnal variation of $\mathrm{NO}_{\mathrm{x}}$, ToN, ToV and PM10 at working days, Saturdays and Sundays. Plotted are averages based on ca. 800 half hourly samples with simultaneous measurements at VVHL, LVBY and HCOE. $\mathrm{NO}_{\mathrm{x}}$ was not observed at VVHL. Due to missing observations the averages of PM10 at VVHL are not fully synchronised with the observations at LVBY and HCOE and in parts omitted.

sometimes higher levels than at LVBY. On weekends the averaged values are based on a lower number of data points and the diurnal pattern is less prominent since the correlation with meteorology and the episodic behaviour dominates over the variation of the urban source. The overall variations and the concentration levels of PM10 and ToV are very similar at all the stations, while more differences in the amplitude of the variations are observed for $\mathrm{ToN}$ and $\mathrm{NO}_{\mathrm{x}}$.

\subsection{Correlations}

In this section we discuss the correlation between half-hourly time series of ToV, ToN, PM10 and $\mathrm{NO}_{\mathrm{x}}$ measured at the three stations HCOE, LVBY and VVHL. The correlation coefficient $(R)$ for time series of the same compound measured at different stations is shown in Table 2. Since not all instruments were always in operation, the number of sample points, that are available for the correlation estimate, is variable with the parameter combination from 652 to 3696 . This should be considered when comparing correlation coefficients. Highest correlation coefficients are observed for ToV between all three stations. This shows the dominating long-range transport origin of ToV. High values of R also appear for PM10 between stations HCOE-LVBY and HCOEVVHL, indicating again the long-range character of PM10. The correlation for PM10 is not as high between the stations LVBY-VVHL. This is probably caused by the relative small number of available data points (only 652). Comparatively
Table 2. Correlation coefficient $(R)$ for one compound measured at different stations (inter station correlation) based on half hourly values. Values of $R$ larger than 0.6 are displayed in bold face. $N$ stands for the number of samples for each combination.

\begin{tabular}{cccc}
\hline \multirow{2}{*}{ Compound } & \multicolumn{3}{c}{ Correlation between stations } \\
& HCOE & HCOE & LVBY \\
& LVBY & VVHL & VVHL \\
\hline ToV & $\mathbf{0 . 8 2}$ & $\mathbf{0 . 8 5}$ & $\mathbf{0 . 7 8}$ \\
$N$ & 1461 & 3004 & 1162 \\
& & & \\
ToN & 0.58 & 0.26 & 0.30 \\
$N$ & 1461 & 3004 & 1162 \\
& & & \\
PM10 & $\mathbf{0 . 7 6}$ & $\mathbf{0 . 6 4}$ & 0.41 \\
$N$ & 1690 & 2191 & 652 \\
& & & \\
NO $_{\mathrm{x}}$ & $\mathbf{0 . 6 1}$ & & \\
$N$ & 3696 & & \\
\hline
\end{tabular}

Table 3. Correlation coefficient $(R)$ between different compounds measured at one station (inner station correlation) based on half hourly values. Values of $R$ larger than 0.6 are displayed in bold face. $N$ stands for the number of samples for each combination.

\begin{tabular}{ccccccc}
\hline \multirow{2}{*}{ Station } & \multicolumn{7}{c}{ Correlation between measured compounds } \\
& ToN & ToN & ToN & ToV & ToV & PM10 \\
& ToV & PM10 & NO $_{x}$ & PM10 & NO $_{x}$ & NO $_{x}$ \\
\hline HCOE & 0.44 & 0.51 & $\mathbf{0 . 8 3}$ & $\mathbf{0 . 7 9}$ & 0.42 & 0.59 \\
$N$ & 3697 & 3098 & 3347 & 3098 & 3347 & 3369 \\
& & & & & & \\
LVBY & 0.59 & 0.43 & $\mathbf{0 . 7 8}$ & $\mathbf{0 . 6 7}$ & 0.54 & 0.35 \\
$N$ & 1873 & 1502 & 1787 & 1502 & 1787 & 1630 \\
& & & & & & \\
VVHL & 0.24 & 0.30 & & $\mathbf{0 . 9 0}$ & & \\
$N$ & 3490 & 2281 & & 2281 & & \\
\hline
\end{tabular}

high $\mathrm{R}$ values are estimated for $\mathrm{NO}_{\mathrm{x}}$ and $\mathrm{ToN}$ between the stations HCOE-LVBY. This can be explained by the common influence of the urban source at these two stations. ToN at VVHL is not well correlated with ToN at HCOE or LVBY, since a) very little urban influence is observed at VVHL and b) the particle formation events at VVHL are not present in the same extend at HCOE and LVBY.

The correlation coefficient between different compounds measured at the same station is given in Table 3. Highest values of $\mathrm{R}$ are observed for the parameter combinations ToN$\mathrm{NO}_{\mathrm{x}}$ and ToV-PM10 at all stations (except that $\mathrm{NO}_{\mathrm{x}}$ was not observed at VVHL). The high correlation between ToN and $\mathrm{NO}_{\mathrm{x}}$ is caused by the fact that both compounds originate to large extend from the traffic emissions. The parameters ToV and PM10 are both closely related to long-range transport and are therefore well correlated. 

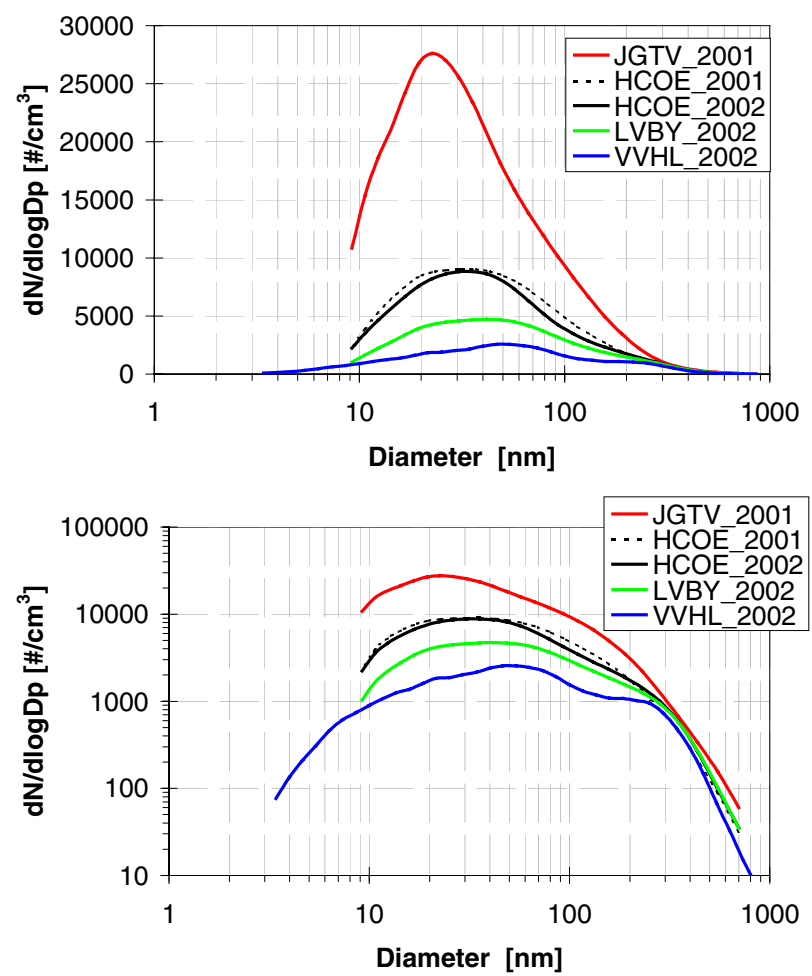

Fig. 5. Average size distribution at four locations during two periods in 2001 and 2002, only working days included. Both linear (top) and logarithmic (bottom) plots regarding the number concentration are given. In Sep-Nov 2002 ca. 2.5 weeks of simultaneous data were collected at 3 stations VVHL (rural), LVBY (near-city), and HCOE (urban). For comparison results of ca. 12 weeks of parallel measurements from Jagtvej (JGTV, kerbside) and HCOE, in MayNov 2001 (Ketzel et al. 2003) are included.

\subsection{Size distribution}

The following sections will focus on the discussion of the measured average particle size distribution and its dependence on time of the day.

\subsubsection{Average}

Figure 5 shows the average particle size distribution for working days. Besides the observations at all three locations HCOE, LVBY and VVHL also data from a previous measuring campaign in 2001 (Ketzel et al., 2003) at HCOE and a kerbside location (JGTV) are shown for comparison. For particle diameters smaller than $200 \mathrm{~nm}$ a pronounced difference in the concentrations is observed between kerbside, urban, near-city and rural level. Between each level the concentrations decrease with about a factor of two. These small particles dominate the total particle number concentration (ToN) and average values of ToN are given in Table 1 for the different locations. The maximum in the size distribution shifts with increasing concentration towards smaller

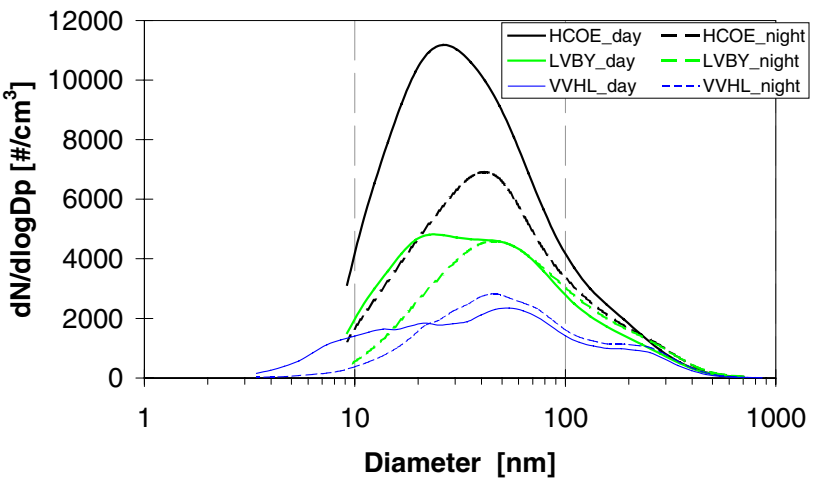

Fig. 6. Size distribution at the three locations under day time (8:0018:00) and night (22:00-5:00) conditions.

diameters, from about $50-60 \mathrm{~nm}$ at the rural site to $20-30 \mathrm{~nm}$ at kerbside. The concentration gradient towards urban and street location points towards a significant urban (traffic) source for this particle size range.

The concentrations of particles larger than $200 \mathrm{~nm}$, which represent the main part of the total particle volume (ToV) are very similar at all the measuring sites, less than $30 \%$ difference between HCOE and VVHL (Table 1). For this size range the urban source contribution is apparently much smaller compared to the regional background.

The VVHL size distribution can be separated into ca. 3 modes, nucleation mode $(10 \mathrm{~nm})$, Aitken mode $(40-50 \mathrm{~nm})$ and accumulation mode $(200-300 \mathrm{~nm})$ and is even better visible in the VVHL distributions shown in Fig. 6 and Fig. 8. This 3-modal structure is usually observed for aged aerosol and typical at rural and natural levels (Mäkelä et al., 2000; Tunved et al., 2003). The remaining stations show a more smooth size distribution without a clear separation between e.g. Aitken and accumulation mode. This smooth distribution is a consequence of the contribution of several urban sources (i.e. traffic and other combustion) emitting over a wide range of particle sizes below $200-300 \mathrm{~nm}$. The principal shape of our observed size distributions is consistent with observations in other urban areas (Putaud et al., 2002; Wehner and Wiedensohler, 2003; Bukowiecki et al., 2003).

\subsubsection{Day- night variation}

Figure 6 depicts the variation of the size distribution between daytime (8-18) and night (22-5) at the three sites HCOE, LVBY and VVHL. The influence of the traffic source during daytime is visible at HCOE and LVBY in the 10-200 nm and 10-40 nm diameter range, respectively. LVBY and VVHL show lower concentrations at daytime in the $80-300 \mathrm{~nm}$ size range (for VVHL even down to $20 \mathrm{~nm}$ ). This is probably due to better mixing during day time hours, i.e. higher WS and higher mixing layer. The influence of the higher urban emissions during daytime can obviously not compensate for 


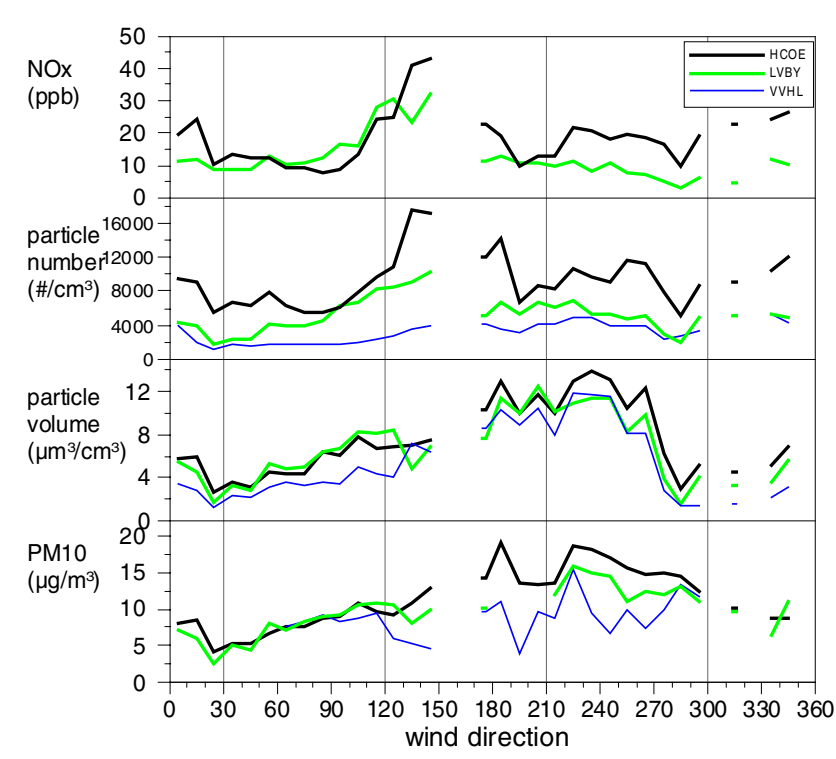

Fig. 7. Wind direction dependence of $\mathrm{NO}_{\mathrm{x}}$, ToN, ToV and PM10. Plotted are averages in $10^{\circ} \mathrm{WD}$ intervals based on ca. 590 half hourly samples with simultaneous measurements at VVHL, LVBY and HCOE (only working days). WD with very low number of data are omitted. Due to missing observations the averages of PM10 at VVHL are not fully synchronised with the observations at LVBY and HCOE.

the better mixing at the near-city and rural level. At VVHL higher concentrations at daytime were found in the nucleation mode (diameters less than $20 \mathrm{~nm}$ ), caused by particle formation events that are observed at VVHL, especially but not exclusively in connection with high global radiation and low concentration of pre-existing particles.

\subsection{Wind direction dependence}

WD is a crucial parameter for the regional pollution as it indicates the origin of the air mass and the relative position of the measuring sites to the main sources (e.g. up- or down wind from Copenhagen). Therefore the concentrations of $\mathrm{NO}_{\mathrm{x}}$ ToN, ToV and PM10 were plotted against WD (Fig. 7). The meteorological conditions (e.g. WS and mixing height) and the long-range contribution are variable with WD and will influence the overall concentration levels at all stations in a similar way. The interesting information in Fig. 7 comes from the concentration levels at the different stations relative to each other. For easterly winds $\left(30^{\circ}-120^{\circ}\right)$ high concentrations at LVBY relative to $\mathrm{HCOE}$ were observed due to contributions form sources from the Copenhagen area. Especially the concentrations of $\mathrm{NO}_{\mathrm{x}}$, ToV and PM10 at LVBY reach or exceed the levels at HCOE. For ToN the ratio LVBY to $\mathrm{HCOE}$ shows highest values around $90^{\circ}-120^{\circ}$ and a trend towards lower ratios for WD $30^{\circ}-90^{\circ}$. For the latter northeasterly WD the distance to the source regions (e.g. Hillerød and Helsingør in Fig. 1) becomes larger and the removal of small particles can take place during a longer transport time of the air mass. For the remaining WD the concentration levels at HCOE are in general higher than at LVBY, indicating the urban source contribution.

In addition the measured data were grouped in four WD sectors (Fig. 8). The sector limits are shown in Fig. 2 and Fig. 7.

WD from west (Fig. 8a) is associated with lower than average concentrations at LVBY (upwind from Copenhagen) and higher concentrations at VVHL (here located downwind of Copenhagen area and other sources in the Øresund region, e.g. Malmö, Helsingborg and Landskrona). As a result the concentration levels at LVBY and VVHL are approaching each other.

Easterly winds (Fig. 8b) bring very clean air to VVHL and also at HCOE the concentration levels are lower than average. This trend to lower concentrations is not observed at LVBY, which is now located in the plume of the Copenhagen area. In this case the concentrations of particles bigger than 80-100 nm are very similar at LVBY and HCOE.

WD from south (Fig. 8c) is associated with continental and therefore more polluted air masses. Concentrations higher than average are observed al all stations for particles bigger than $10-15 \mathrm{~nm}$. Nucleation range concentrations $(<15 \mathrm{~nm})$ at VVHL are suppressed by the higher concentration of bigger particles.

WD from north (Fig. 8d) brings reduced particle concentrations for all stations for particles bigger than 50-100 nm compared to the total average. This "relatively clean" air favours particle formation (photochemical driven nucleation events) resulting in particle concentrations in the $10-20 \mathrm{~nm}$ size range that are higher than average at all stations, but most pronounced at VVHL.

In summary it can be concluded that the location of the stations relative to the source regions (upwind or downwind) can well explain the observed variations in particle size distribution with WD.

\subsection{Street versus urban contribution}

In this section we compare the size distribution of the "street traffic source", estimated by the difference kerbside - urban level, with the "average urban source", estimated by the difference urban level (HCOE) minus near-city level (LVBY). The here addressed question is: Does the relative shape of the particle size distribution, e.g. the position of the maximum, and the particle concentration, e.g. relative to an inert tracer, change between street level and urban background? The traffic source contribution was measured at two streets in Copenhagen (JGTV and HCAB) over several periods in 2001/2002. In the analysis only that subset of data were used for which also measurements at HCOE were performed and therefore allows subtracting the urban background from the kerbside data. Figure 9 depicts the obtained size distribution differences JGTV-HCOE and HCAB-HCOE that characterise the 

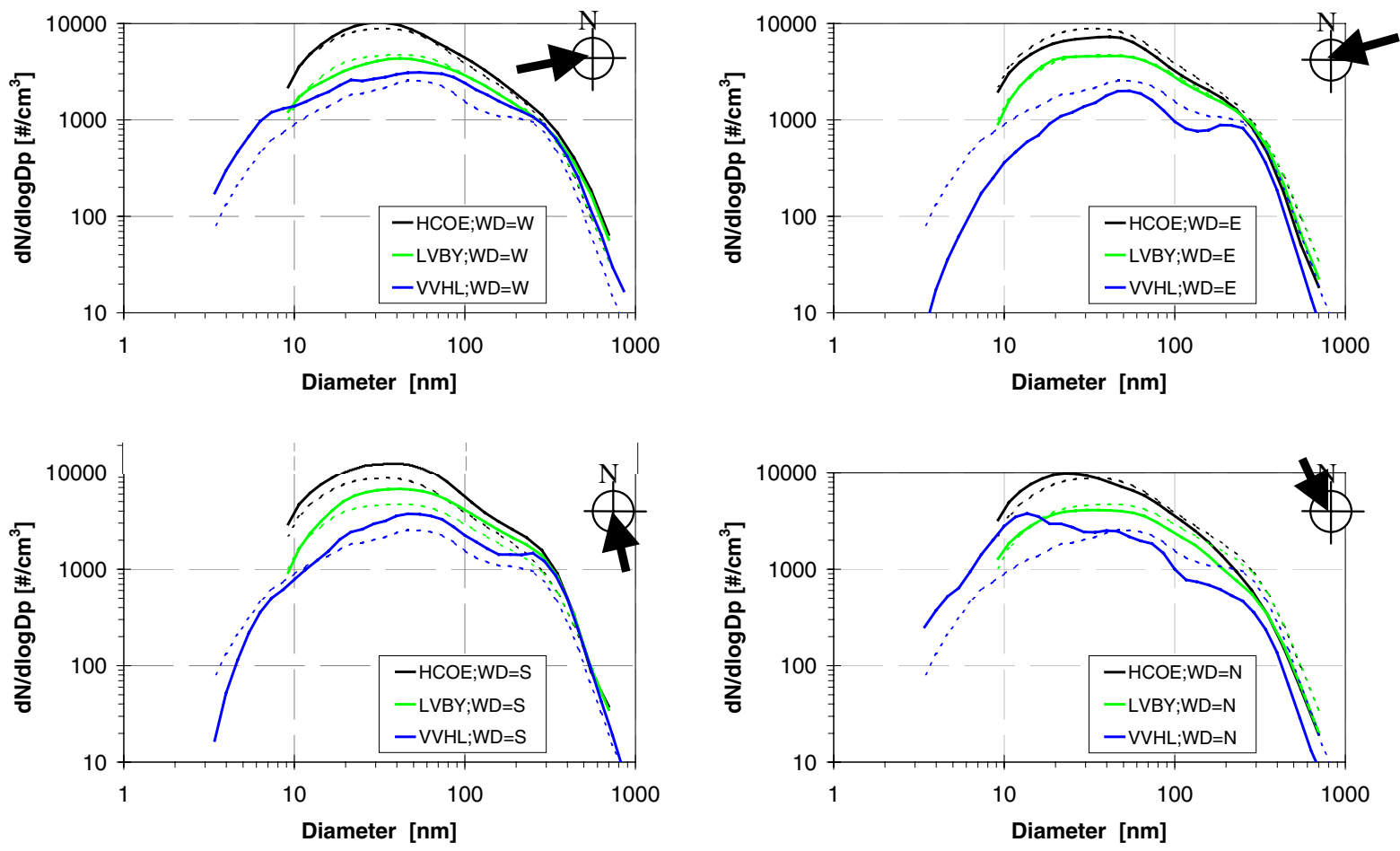

Fig. 8. Size distribution at the three locations for different wind direction sectors. From top left to bottom right: West, East, South and North. For better comparison all plots include the total averages from Fig. 5 as dashed curves.

"fresh" traffic source under average conditions. Figure 9 further contains the difference HCOE-LVBY (urban minus near-city) for the WD sector west $\left(210^{\circ}-300^{\circ}\right)$. The size distributions in Fig. 9 are normalised with their total number concentration in order to be able to plot them in one diagram and compare the shape of the curves. The WD west was chosen, since LVBY represents for this sector the concentration of the air mass up-wind of Copenhagen and the difference HCOE-LVBY is a valid approximation for the size distribution emitted from the "average" urban source. The urban source shows a particle size distribution slightly shifted to bigger particle diameters. The maximum in the size distribution is shifted to about $28 \mathrm{~nm}$ in comparison to the traffic distribution with a maximum at $22 \mathrm{~nm}$. Removal processes that are most efficient for smallest particles $(<20 \mathrm{~nm})$ as e.g. deposition and coagulation might be the responsible mechanism for this. Condensational growth could also contribute to the shift of particle size.

The total particle number $(\mathrm{ToN})$ and $\mathrm{NO}_{\mathrm{x}}$ concentrations are well correlated as shown in Sect. 3.2 due to their common sources. This good correlation allows for investigation of the change of ToN relative to $\mathrm{NO}_{\mathrm{x}}$, latter can be regarded as inert on urban scale. The data points $\mathrm{ToN}$ versus $\mathrm{NO}_{\mathrm{x}}$ plotted in Fig. 10 were averaged separately for each hour of a working day at two kerbside, one urban and one near-city location including a linear regression line. The kerbside plots

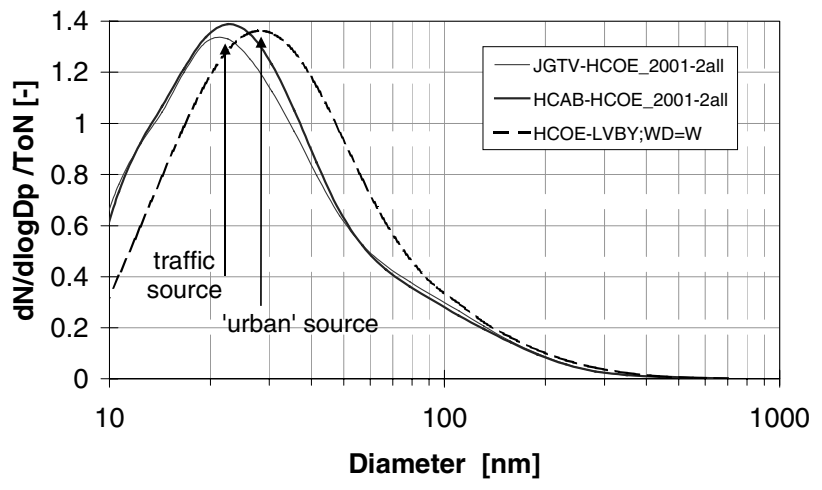

Fig. 9. Comparison of the average size distributions of the street-traffic source (JGTV and HCAB) and the total urban source (HCOE). From the average size distributions we subtracted the simultaneous measured background, i.e. street minus urban background (HCOE) and urban background minus rural background (LVBY). Only WD west was selected for the urban source estimate. The differences were normalised with the total number concentration.

are based on the above described average data set from JGTV and $\mathrm{HCAB}$, while the urban and near-city data originate from the campaign in fall 2002. For the kerbside and urban stations the diurnal variations of $\mathrm{NO}_{\mathrm{x}}$ and $\mathrm{ToN}$ show a very good correlation $\left(\mathrm{R}^{2} \geq 0.92\right)$ indicating the common sources. 


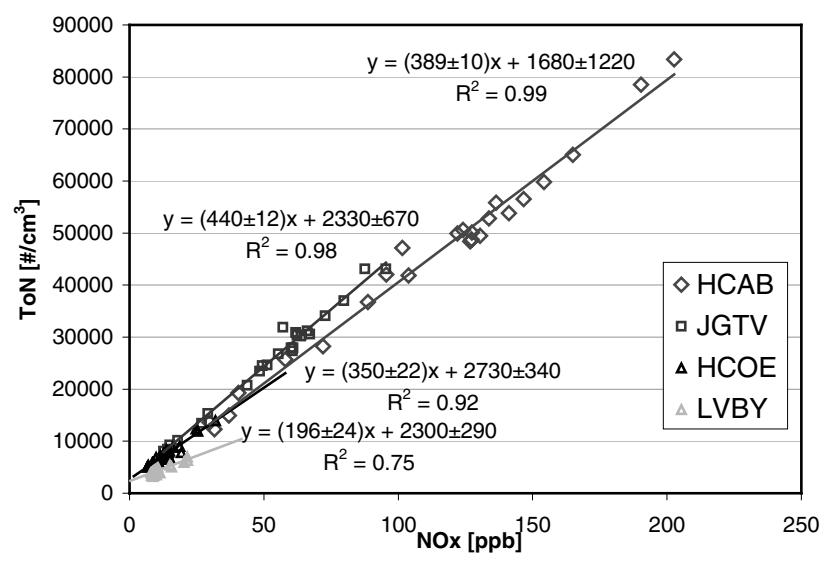

Fig. 10. Scatter diagram of ToN versus $\mathrm{NO}_{\mathrm{x}}$ for four different locations: kerbside (HCAB, JGTV), urban (HCOE) and near-city (LVBY). Data are averaged separately for each hour of the day, only working days included. Linear regression lines are shown for each station. Regression formulas are given including one standard deviation.

The slope of the regression lines reveals how many particles (in $\mathrm{cm}^{-3}$ ) per $\mathrm{NO}_{\mathrm{x}}$ (in ppb) are present at the different stations. The range for the slope at kerbside is ca. 380-450 including values from two stations and one standard deviation as error estimate. At urban level (HCOE) the slope covers a range of ca. 260-380 including three different sample periods (only one of which is shown in Fig. 10 for better clarity of the graph). Thus the slope $\mathrm{ToN}$ vs. $\mathrm{NO}_{\mathrm{x}}$ at urban level is about 15-30\% smaller compared to the kerbside level. This means that particles get removed by e.g. deposition and coagulation on their way from the kerbside to the urban level. This is based on the assumption that $\mathrm{NO}_{\mathrm{x}}$ can be regarded as inert at urban scale and that the two kerbside measurements are representative for the average urban source that is affecting the HCOE station. At the near-city station (LVBY) the correlation between ToN and $\mathrm{NO}_{\mathrm{x}}$ daily variation is substantially lower $\left(R^{2}=0.75\right)$ since the daily variations are smaller compared to the average levels (see Fig. 4). Moreover unusually high $\mathrm{NO}_{\mathrm{x}}$ values (relative to HCOE) were observed at LVBY during this measuring campaign. The ratio LVBY/HCOE for $\mathrm{NO}_{\mathrm{x}}$ was 0.77 for compared to 0.56 for the whole year 2002 (both for working days). The higher $\mathrm{NO}_{\mathrm{x}}$ values will decrease the slope and the lower correlation makes the estimate of the slope ToN vs. $\mathrm{NO}_{\mathrm{x}}$ more uncertain. The slope of the regression line at LVBY is with 170-220 (Fig. 10) significantly smaller compared to HCOE and kerbside. This indicates a further removal of particles (relative to $\mathrm{NO}_{\mathrm{x}}$ ) during the transport from urban to near-city location, but could partly be caused by the before mentioned elevated $\mathrm{NO}_{\mathrm{x}}$ levels at LVBY. The quantification of the two effects is very uncertain due to the limited time series of available measurements and will not attempted here.

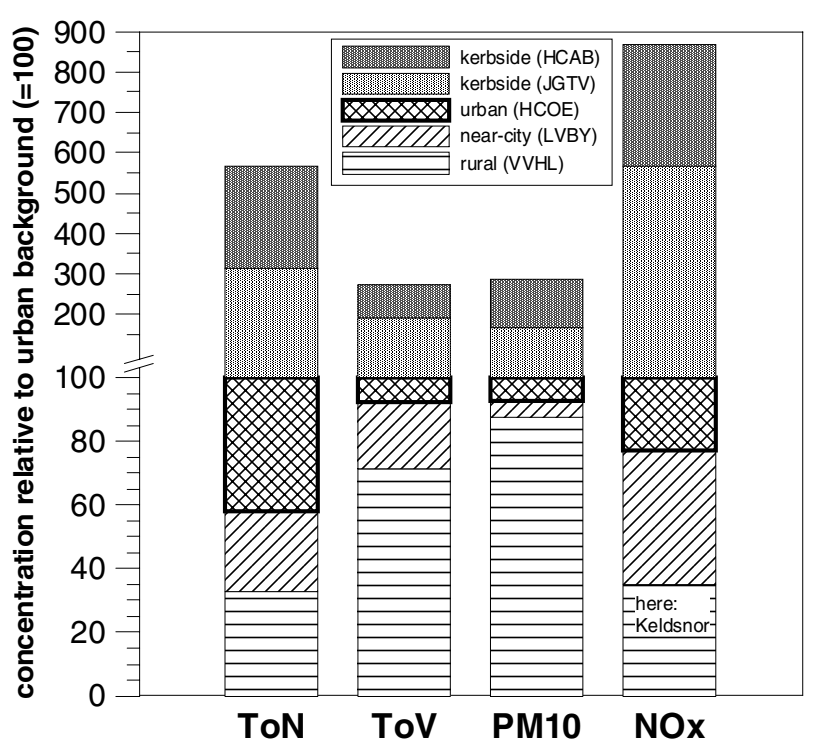

Fig. 11. Comparison of average concentrations of total particle number (ToN), total particle volume (ToV), PM10 and $\mathrm{NO}_{\mathrm{x}}$ at rural, near-city, urban and kerbside stations relative to urban background levels. The concentration bars are stacked so that only the additional contributions are marked with the pattern shown in the legend. The elevation of the urban background (HCOE) above the near-city level is marked (bold frame) and represents the potential for urban emissions reduction measures to decrease urban concentrations. Note that the scale of the vertical axis changes at 100. Since $\mathrm{NO}_{\mathrm{x}}$ was not measured at VVHL data from another rural station (Keldsnor) were used.

The intercept of the regression lines in Fig. 10 represents an estimate of a "clean" regional background of ToN that is not influenced by local contribution, i.e. we assume $\mathrm{NO}_{\mathrm{x}}$ concentrations to be zero in this "clean" background. The intercept for most of the regression lines lies in the range 2000$3000 \mathrm{\#} \mathrm{cm}^{-3}$, which is in agreement to the average value at the rural station VVHL of $2500 \mathrm{Acm}^{-3}$. Only the intercept of the $\mathrm{HCAB}$ regression line is with $1700 \# \mathrm{~cm}^{-3}$ below this range, but the much higher standard deviation of this value compared to the other regression results indicates a higher uncertainty for this estimate.

\subsection{Urban versus regional contribution}

In this final part of the discussion we want to illustrate the contribution from the urban sources relative to the regional background levels. The question is: How much decrease in the urban concentration levels can be expected by a certain reduction in urban emissions e.g. in form of traffic regulations or more stringent vehicle emission limits?

Figure 11 shows the average working day concentration levels at the different locations (see Table 1) relative to the levels at HCOE $(=100 \%)$. The near-city levels of PM10 and ToV contribute to ca. $93 \%$ to the urban concentrations and 
only 7\% of the urban PM10 and ToV concentrations originate from local urban sources. The long-range transport is apparently the dominating source.

For ToN as well as $\mathrm{NO}_{\mathrm{x}}$ a much bigger difference between rural and urban levels could be observed. Near-city concentrations are about $58 \%$ of the urban levels for ToN and $77 \%$ for $\mathrm{NO}_{\mathrm{x}}$. Hence, the local emissions contribute with $42 \%$ and $23 \%$ to the urban concentrations of $\mathrm{ToN}$ and $\mathrm{NO}_{\mathrm{x}}$, respectively.

The potential for reducing urban concentrations by emission control is obviously much higher for $\mathrm{ToN}$ and $\mathrm{NO}_{\mathrm{x}}$ compared to PM10 and ToV. Taking into account the supposed stronger health effects of ultrafine particles (that dominate $\mathrm{ToN}$ ) reduction measures should address particle number emissions.

In addition the kerbside concentration levels are also plotted in Fig. 11 relative to urban (HCOE) concentrations. Here a similar behaviour is observed regarding higher relative concentrations of $\mathrm{ToN}$ and $\mathrm{NO}_{\mathrm{x}}(300 \%-850 \%$ relative to $\mathrm{HCOE})$ pointing at a higher reduction potential compared with $\mathrm{ToV}$ and PM10 (150\%-300\% relative to $\mathrm{HCOE})$.

\section{Conclusions, implications and outlook}

A campaign of simultaneous measurements of particle size distribution and PM10 at three locations representing urban, near-city and rural level is reported.

PM10 and total particle volume (ToV) are well correlated between the three different stations showing similar concentration levels, in average within 30\% relative difference. ToV and PM10 are also well correlated within each location. Episodes of elevated concentrations of ToV and PM10 with length of 2-3 days are observed. A diurnal variation with the traffic behaviour is not very clear. All this indicates a common source from long-range transport that dominates the concentrations at all levels.

Moreover $\mathrm{NO}_{\mathrm{x}}$ and total particle number (ToN) are well correlated at the urban and near-city level and show a distinct diurnal variation, both indicating the common traffic source. The average concentration levels at the three stations differ by a factor of 3 . The observed concentrations are $2500 \mathrm{~cm}^{-3}, 4500 \# \mathrm{~cm}^{-3}$ and $7700 \mathrm{~cm}^{-3}$ at rural, nearcity and urban level, respectively.

Comparing the size distribution at day versus night times on working days reveals the contribution of the traffic source in the $10 \mathrm{~nm}-200 \mathrm{~nm}$ size range at urban level. The maximum of the size distribution shifts from about $20-30 \mathrm{~nm}$ at kerbside to $50-60 \mathrm{~nm}$ at rural level. Particle formation events are observed in the $3-20 \mathrm{~nm}$ size range at rural level in the afternoon hours, mostly under conditions with low concentrations of pre-existing aerosol particles.

The variation of the particle size distributions with wind direction (WD) could be demonstrated and explained by the location of the stations relative to the source regions, upwind or downwind depending on WD. This shows the consistency of the measurements and opens the possibility to study the particle transformation processes inside the plume of an urban area. The maximum in the size distribution of the "average urban source" seems to be shifted to about $28 \mathrm{~nm}$ compared to $22 \mathrm{~nm}$ from the 'fresh kerbside traffic source'. Using the good correlation of ToN with $\mathrm{NO}_{\mathrm{x}}$ and assuming $\mathrm{NO}_{\mathrm{x}}$ to be inert on urban scale reveals that the particle number at urban level is reduced by $15-30 \%$ compared to kerbside. Particle removal processes, e.g. deposition and coagulation, which are most efficient for smallest particle sizes $(<20 \mathrm{~nm})$ and condensational growth are likely mechanisms for the loss of particle number and the shift in particle size.

The potential for decreasing urban concentrations by reduction of local emission was discussed by comparing the urban and regional contributions to the pollution levels. Reduction measures concerning $\mathrm{NO}_{\mathrm{x}}$ and ToN are likely to effect both the street level and urban background concentrations, while for PM10 and ToV only measurable effects at the street level are probable. Taking into account the supposedly stronger health effects of ultrafine particles reduction measures should address particle number emissions.

The results of the here reported measuring campaign will build a basis for modelling studies on the particle transformation processes in the urban and regional scale. More valuable results could be obtained by a longer similar campaign, that allow to study the seasonal variations and the particle- $\mathrm{NO}_{\mathrm{x}}$ relation at the near-city station, where unusually high $\mathrm{NO}_{\mathrm{x}}$ values were observed during this campaign.

Acknowledgements. The work presented in this paper is part of $\mathrm{M}$. Ketzel's Ph.D. work supported by the Danish Research Agency. The Danish EPA under the Danish Ministry of Environment provided funding for the Danish particle research programme AIDA (Aerosols in Danish Air) (Palmgren et al., 2003). Data of the gas pollutants and meteorological (HCOE) data were provided from the National Air Quality Monitoring Programme (LMP). The DMPS measurements at HCOE were supported by the Danish Natural Science Research Council. The authors thank the Wind Energy and Atmospheric Physics Department at Ris $\varnothing$ National Laboratory for providing us with meteorological measurements at LVBY. The measurements at the Swedish site are supported by the Swedish Foundation for Strategic Environmental Research (MISTRA) as part of the Swedish air pollution research program ASTA (International and National Abatement Strategies for Transboundary Air Pollution).

\section{References}

APEG: Source Apportionment of Airborne Particulate Matter in the United Kingdom. Report of the Airborne Particles Expert Group, Department of the Environment, Transport and the Regions, the Welsh Office, the Scottish Office and the Department of the Environment (Northern Ireland), 1999.

Bukowiecki, N., Dommen, J., Prévôt, A. S. H., Weingartner, E. and Baltensperger, U.: Fine and ultrafine particles in the Zürich (Switzerland) area measured with a mobile laboratory, An as- 
sessment of the seasonal and regional variation throughout a year, Atmos. Chem. Phys., 3, 1477-1494, 2003.

DMI: Danish Meteorological Institute, http://www.dmi.dk/vejr/ aktuelt/200303241530/index_nyhed.html, 2003.

Ferm, M. and Hansson, H.-C.: Jämförelse mellan de två vanligaste metoderna att mäta PM10 i Sverige (In Swedish), IVL Swedish Environmental Research Institute Ltd, IVL Rapport/report B1527, 2003.

Jacobson, M. Z.: Strong radiative heating due to the mixing state of black carbon in atmospheric aerosols, Nature, 409, 695-697, 2001.

Jokinen, V. and Mäkelä, J. M.: Closed-loop arrangement with critical orifice for DMA sheath/excess flow system, J. Aeros. Sci., 28, 643-648, 1997.

Kemp, K. and Palmgren, F.: The Danish Air Quality Monitoring Programme, Annual Report for 2002, National Environmental Research Institute, Roskilde, Denmark, NERI Technical Report No. 450, 2003.

Ketzel, M., Wåhlin, P., Berkowicz, R., and Palmgren, F.: Particle and trace gas emission factors under urban driving conditions in Copenhagen based on street and roof-level observations, Atmos. Envir., 37, 2735-2749, 2003.

Künzli, N., Kaiser, R., Medina, S., Studnicka, M., Chanel, O., Filliger, P., Herry, M., Horak Jr., F., Puybonnieux-Texier, V., Quénel, P., Schneider, J., Seethaler, R., Vergnaud, J.-C., and Sommer, H.: Public-health impact of outdoor and traffic-related air pollution: a European assessment, Lancet, 356, 795-801, 2000.

Mäkelä, J. M., Koponen, I. K., Aalto, P., and Kulmala, M.: Oneyear data of submicron size modes of tropospheric background aerosol in southern finland, J. Aeros. Sci., 31, 595-611, 2000.

Palmgren, F., Wåhlin, P., Berkowicz, R., Ketzel, M., Illerup, J. B., Nielsen, M., Winther, M., Glasius, M., and Jensen, B.: Aerosols in Danish Air (AIDA), Mid-term report 2001-2002, National Environmental Research Institute, Roskilde, Denmark, NERI Technical Report No. 460, http://www.dmu.dk/1_Viden/ 2_Publikationer/3_fagrapporter/rapporter/FR460.PDF, 2003.
Putaud, J. P., Van Dingenen, R., Baltensperger, U., et al.: A European Aerosol Phenomenology - physical and chemical characteristics of particulate matter at kerbside, urban, rural and background sites in Europe, European Commission and Joint Research Centre, EUR 20411 EN, http://ies.jrc.cec.eu.int/ Download/cc, 2002.

Seaton, A., MacNee, W., Donaldson, K., and Godden, D.: Particulate air pollution and acute health effects, Lancet, 345, 176-178, 1995.

Tunved, P., Hansson, H.-C., Kulmala, M., Aalto, P., Viisanen, Y., Karlsson, H., Kristensson, A., Swietlicki, E., Ström, J., and Komppula, M.: One year boundary layer aerosol size distribution data from five Nordic background stations, Atmos. Chem. Phys., 3, 2183-2205, 2003.

Wåhlin, P. and Palmgren, F.: Source apportionment of PM10 and PM2.5 in a street in Copenhagen, Presented at "Particulate Matter: Atmospheric Sciences, Exposure and the Fourth Colloquium on PM and Human Health", 31 March-4 April, 2003, Pittsburgh, Pennsylvania, USA, 2003.

Wehner, B. and Wiedensohler, A.: Long term measurements of submicrometer urban aerosols: statistical analysis for correlations with meteorological conditions and trace gases, Atmos. Chem. Phys., 3, 867-879, 2003.

Wichmann, H. E. and Peters, A.: Epidemiological evidence of the effects of ultrafine particle exposure, Phil. Trans. R. Soc. Lond. A ,358, 2751-2769, 2000.

Wiedensohler, A.: An Approximation of the Bipolar ChargeDistribution for Particles in the Sub-Micron Size Range, J. Aeros. Sci., 19, 387-389, 1988.

Winklmayr, W., Reischl, G. P., Lindner, A. O., and Berner, A.: A New Electromobility Spectrometer for the Measurement of Aerosol Size Distributions in the Size Range from 1 to $1000 \mathrm{~nm}$, J. Aeros. Sci., 22, 289-296, 1991. 